This item was submitted to Loughborough's Research Repository by the author.

Items in Figshare are protected by copyright, with all rights reserved, unless otherwise indicated.

\title{
An industrial evaluation of an Industry 4.0 reference architecture demonstrating the need for the inclusion of security and human components
}

PLEASE CITE THE PUBLISHED VERSION

https://doi.org/10.1016/j.compind.2019.02.007

PUBLISHER

(C) Elsevier

VERSION

AM (Accepted Manuscript)

\section{PUBLISHER STATEMENT}

This paper was accepted for publication in the journal Computers in Industry and the definitive published version is available at https://doi.org/10.1016/j.compind.2019.02.007

LICENCE

CC BY-NC-ND 4.0

\section{REPOSITORY RECORD}

Sharpe, Richard, Katherine A.J. van Lopik, Aaron D. Neal, Paul Goodall, Paul Conway, and Andrew West. 2019. "An Industrial Evaluation of an Industry 4.0 Reference Architecture Demonstrating the Need for the Inclusion of Security and Human Components". Loughborough University. https://hdl.handle.net/2134/37001. 


\title{
An industrial evaluation of an Industry 4.0 reference architecture demonstrating the need for the inclusion of security and human components
}

\begin{abstract}
The research presented in this paper looks at evaluating RAMI4.0, a Research Architecture (RA) designed for Industry 4.0, through the representation of an existing Cyber-Physical System's (CPSs) key functionality. The use case represented is that of a UK firm refurbishing End of Life (EoL) IT devices for business clients. EoL refurbishment is a domain with many complexities due to an inherent business model which results in varying quantities, types and conditions of received devices. These uncertainties can generally not be addressed until the devices have arrived in the facility and are inspected. RAs are an important tool used in system development to represent functionality, this representation should be high level and allow the easy communication of key concepts for not only client-to-developers and developer-to-developer but also either to an audience. An appropriate RA will help industrialists to understand what Industry 4.0 means to them (i.e. increased flexibility and control) and the functionality of any system potentially being invested in. The results of this research included two proposals for the extension of RAMI4.0 regarding the representation of security and humans within the systems. While Industry 4.0 focusses on CPSs this work also makes a further recommendation that the focus of modelling should be shifted to Cyber-Physical Human Systems (CPHSs) to ensure correct consideration of the humans within the system.
\end{abstract}




\section{Introduction}

Industry 4.0 is a now a widely referred to concept, and it promotes the adoption of a more technological and connected approach to manufacturing through the use of Cyber-Physical Systems (CPSs) [1].

The underlying concept of CPSs is the connection between the virtual (or cyber) world and the real (or physical) world [2]. This connection provides the ability to create and update real-time virtual representations of physical assets to populate a "digital twin" [3]. These virtual representations can be manipulated within the cyber world (e.g. simulation and optimisation) and actuate the physical world supporting greater control of manufacturing facilities, production lines or individual machines [4]. Industry 4.0 utilises this technology to support manufacturing firms in addressing individual customer requirements, increasing flexibility, optimising decision making, increasing productivity and resource efficiency while uncovering new value opportunities through the provision of services in addition to their product offerings [5].

While manufacturers have these benefits promoted to them, most manufacturers currently exist in a world of data silos and unconnected resources (i.e. machines)[6]. There is a lack of research demonstrating the key benefits of CPSs to manufacturers [7] which needs to be overcome before manufacturers will risk investment. A study in the UK showed that $56 \%$ of manufacturers in 2016 "have little or no understanding of Industry 4.0", and $44 \%$ believed that this lack of understanding was the primary reason for not investing in Industry 4.0 deployments [8].

If manufacturers are to adopt Industry 4.0 and become integrated horizontally (through the supply chain) and vertically (through assets within their company), then CPSs need to be robust, resilient and cost-efficient[9]. To ensure industry adoption of the Industry 4.0 paradigm, CPSs need to be quick to deploy with attractive ROIs, as well as providing transparent communication of functionality to end users [10]. 
RAs act as both a development aid [11,12], transferring knowledge gained from experience, regulating quality and instructing design [13], and as a tool to communicate system functionality, enabling engineers to understand systems quickly thereby lowering the time and cost associated with system maintenance [11]. Therefore an appropriate and widely adopted RA for Industry 4.0 would model components important to manufacturing (i.e. physical assets and operators) and would be beneficial to those looking to create or specify CPSs for within their facilities.

The aim of the research presented within this paper is to contribute to the development of RAMI4.0, the reference architecture proposed for Industry 4.0, with the goal to get more industrialists investing in CPSs for their factories and facilities. To achieve this a scenario from industry is represented on the architecture, evaluated and then recommendations for future additions to RAMI4.0 presented.

The research presented initially reviews the purpose of RAs along with the roles and types of CPS within Industry 4.0 explained (Section 2). An introduction to RAMI4.0 (Section 3) is then presented followed by an introduction to the industrial case study used for this research (Section 4). The case study was split into three scenarios which have been individually represented onto RAMI4.0 in Section 5. The ability to represent these scenarios has then been discussed (Section 6) alongside recommendations for future revisions of RAMI 4.0.

\section{Use of Reference Architectures and CPSs within the}

\section{manufacturing domain}

A CPS within manufacturing requires the modelling of; physical assets (i.e. machines, conveyors, facilities [14]), humans (active and passive [15]) and software applications \& services (including security [14]).

A human (i.e. operator, worker, machinist) and their interactions with and within a system are an important aspect of system modelling [15]. While much research has been conducted looking at full automation humans are still seen as crucial $[5,16]$. Humans are required to provide governance [17] 
as well as agility and resilience to the many issues arising in complex systems. A human's ability to undertake complex operations, make flexible movements and decisions [18] makes them invaluable in manufacturing. The application of expert, often tacit, human knowledge can be used to solve problems in the face of sparse or missing data [19]. As such it is unlikely that humans will ever be replaced entirely within manufacturing facilities and should, therefore, be considered as part of the Industry 4.0 "movement" $[10,20]$. A successful RA is one which is able to model these elements, their connections and simplify any complexity so that it can be represented and communicated to stakeholders.

Types of CPSs exist that focus on the human interactions within the system; including Socio-CyberPhysical Systems (SCPSs)[21,22], Cyber-Physical-Social Systems (CPSS)[23] and Cyber-Physical Human Systems (CPHSs or CHS) $[10,24,25]$.

SCPSs are social manufacturing systems where the focus lies with end users customising products to their individual needs or desires [21], they do not involve modelling humans within the manufacturing stages of the products and therefore are not relevant to this study. CPSSs are described as an advancement of CPSs to involve humans as part of the system. Wang argues that humans must be included in any system modelling as they have an integral role in the design and operation of a CPS [23]. CPHSs like CPSSs models human interactions within a CPS. CPHSs model humans as a component within the system which differs from more standard component models with the concepts of cognition, predictability and motivation [25]. When human feedback is an integral part of a system, it should be described, modelled and designed as a CPHSs [24].

An RA looks to model a domain and represents the functionality and interactions of a system. As well as the complexity of modelling physical assets there is also the functionality of the software to be represented (the traditional use of RAs), i.e. service composition \& orchestration, security protocols, users and connections [26]. If RAs are to be used to communicate and aid development, then security (highlighted as a challenge for CPS both academically $[27,28]$ and through industrial studies [8]) is also a vital part of any system to be modelled. RAs can also provide guidelines for developers to follow 
ensuring knowledge and lessons learned from previous projects are transferred $[11,26,29]$. RAs themselves can be classed as either research-driven or practice-driven [30]. Research-driven architectures tend to be experimental and un-validated whereas practice-driven architectures have been used and adapted to encapsulate knowledge derived from implementations [30]. The RA designed explicitly for Industry 4.0 (RAMI4.0) [1] has yet to be published being evaluated via industrial usage and, can only be referred to as a research-driven RA. The contribution of the research outlined in this paper is to aid the development of an RA for Industry 4.0, highlighting the issues involved in migrating a research-driven architecture to a practice-driven model.

\section{RAMI4.0}

Figure 1 depicts the central figure of RAMI4.0 proposed for the development of Industry 4.0 systems. RAMI4.0 aims to "describe assets and combination of assets" using a diagram consisting of three dimensions: (i) Layers (i.e. Business, Functional, Information, Communication, Integration and Asset: vertical axis), (ii) Hierarchy Levels (i.e. ranging from Connected Worlds to Products: left hand horizontal axis) and (iii) Life Cycle \& Value Stream (i.e. the Design, Development, Production, Delivery and Maintenance/Usage of unique products: right hand horizontal axis) [1]. Each Layer represents separations of software functionality (i.e. the Business Layer provides Service Orchestration, Modelling of Business Rules, Business Processes) with the software in the same Layer required to be compatible [1]. 


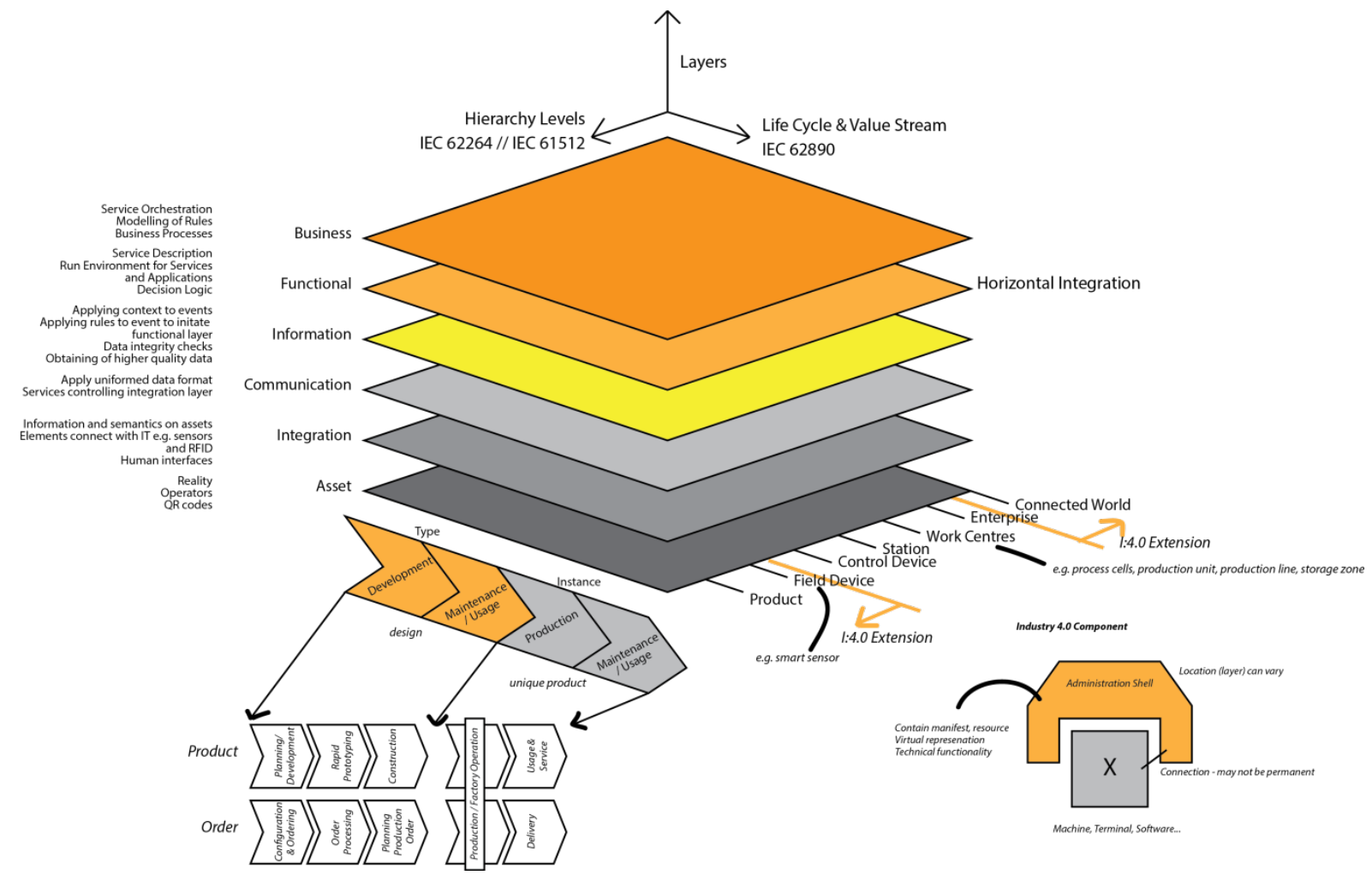

Figure 1 -Summary of RAMI4.0[1]

IEC 62264-1:2013 and IEC 61512-1:1997 describe relevant models and terminology for Enterprisecontrol system integration and Batch control [31,32] and are the basis for the Hierarchy Levels. The RAMI4.0 architecture extends IEC 62264 to include Field Device and Product at the lower levels of granularity and the Connected World at the higher level. The third axis represents the system Life Cycle \& Value Stream. The lifecycle of the product commences when a design is developed and continues when instances of this design are manufactured and have unique identifiers. This axis highlights that different data can be collected through the lifecycle. Examples of the different lifecycle information requirements of a product and an order of collection are shown in Figure 1. The lifecycle model is claimed to hold for any Industry 4.0 component. The Value Stream is the recording and representation within this lifecycle model of any value-adding processes throughout the supply chain, i.e. not constrained just to one factory or facility.

The Asset level is the lowest in the Layers axis which represents the physical world where physical components reside. This layer also includes passive technology such as Quick Response Codes (QR codes) and barcodes [1]. Directly above this is the Integration layer, which holds the information on 
the different assets and connected hardware such as sensors and RFID readers. The Integration layer also holds human interfaces. The Communication layer is used to apply a uniform format to information and data passed through it. It also contains the services used to control the Integration layer. The Information layer is required to apply context to events passed to it and use rules to determine when to initiate the adjacent Functional layer. The Information layer also completes data integrity checks to ensure high-quality data. The Functional layer is where services (including decision logic) are operated and described. It also supports the run-time environment for applications. The uppermost layer is the Business layer, which orchestrates the services [1], can model rules, simulate and apply these to recorded business processes [1].

As well as the three-dimensional architectural model there is also the concept of "Industry 4.0 components" these are defined as "uniquely identifiable participants" and are represented using a representation of the physical object and an "administrative shell", Figure 2 [33].

The RAMI4.0 documentation includes a classification of system components based on their Capability and Presentation, see Figure 2. Only components with a classification of CP24, CP34 or CP44 are Industry 4.0 components as they can communicate and are "administered as an entity" [33].

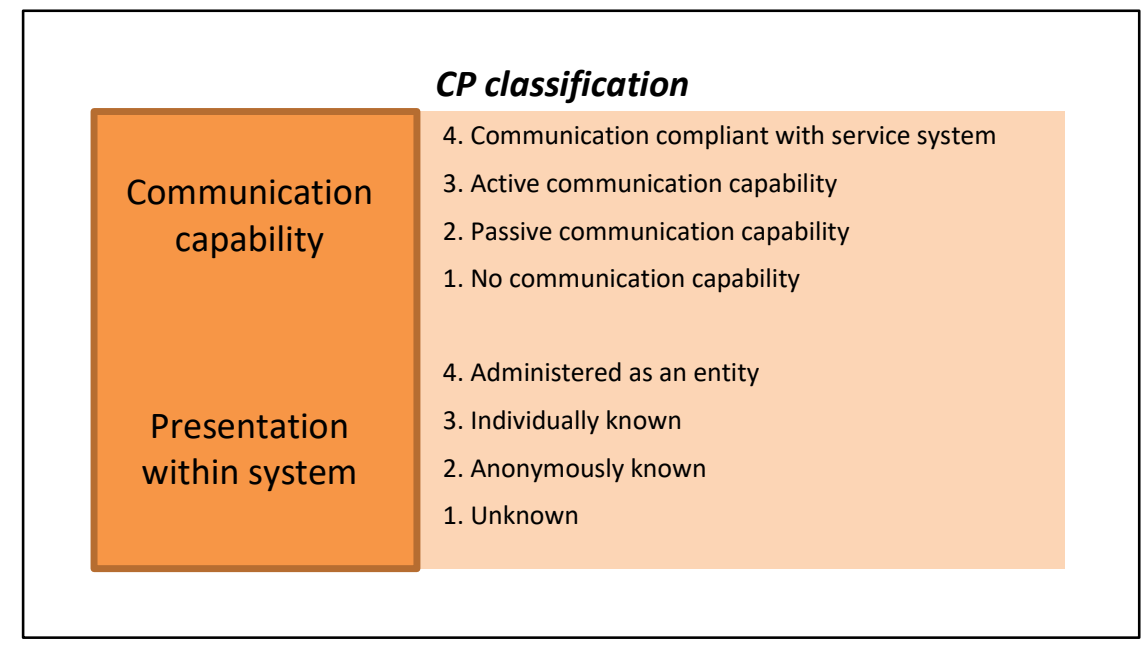

Figure 2 - RAMI4.0 Component Classification

Creating an Industry 4.0 component will be of use to firms who sell devices to other manufacturers to be used within their systems or facilities. The administrative shell can be for a singular device or a collection of devices depending on the application and describes how it is controlled and how it 
communicates with the wider network. The administrative shell also represents accompanying software including a virtual description and 14.0 compliant; services \& states, communication and semantics [1]. The shell itself does not have to reside on the physical asset and what it contains can vary for different applications.

\section{Methodology and Case Study Introduction}

To progress RAMI4.0, it should be evaluated through the representation of industrial scenarios and will be incremental changed \& improved through usage. For this research, an appropriate scenario was selected and represented using RAMI4.0 and a discussion of usage and recommendations presented.

While there are methods of evaluating concrete architectures such as scenario-based [34], mathematical models, software architecture and performance-based methods [35,36], it is not possible to use all of these techniques for an RA [35]. For example, mathematical models and software architecture methods require domain-specific knowledge such as process execution times and predictions of system performance which are difficult to quantify accurately before the system is designed, constructed and implemented [35]. In many cases, these KPIs are often not accurately defined until the project is deployed [35]. An RA comparison framework proposed by Angelov et al. [37] built on their previous study [30] which had used an adaptation of the Architecture Tradeoff Analysis Method (ATAM), however, this is only for comparison and not for the evaluation of RAs. The authors propose instead that to evaluate a RA requires it to be used as designed and it is this process that is discussed.

The system which will be represented on RAMI4.0 operates within the refurbishment of Waste Electronics and Electrical (WEEE) devices. The company who uses the system is based in the UK and is an SME (Small, Medium Enterprises). The refurbisher operates by collecting devices, processing them (inspection, data erasure, repair, cleaning) and if they have residual value they are re-sold back into the market, else they are recycled by their material content. Each device which enters the facility 
has an unknown and unique and so past the results of inspections and other processes determine the next process required (i.e. if it needs a repair). The CPS used controls the processing order for the devices based on their condition, processing results and the device type (i.e. mobile phone, computer, laptop etc.) and this is assessed at the end of each process. The link between the physical and virtual world is realised through the use of passive UHF (Ultra High Frequency) RFID (Radio Frequency Identification).

Through the provision of the refurbishment process control, it also gives the company a high level of visibility of each individual device and its progress. This information is shared with members of its supply chain (e.g. the person supplying the WEEE) through a web-based application. More information on this system can be viewed in [38].

Three scenarios showing parts of key functionality offered by the system will be represented on RAMI4.0:

1. An operator is physically moving a product to a workstation where it automatically identifies the product.

2. Information displayed to the operator regarding how to refurbish the product and the process step which should follow the one being undertaken.

3. A supply chain member is accessing real-time data to see the progress of a product being refurbished.

The objects in the physical world which will require modelling will be a product being refurbished, the RFID technology used for its cyber-to-physical world communication, a system used for an automated process (data erasure) and human operators involved in manual processes. The 'erasure rig' used within the case study facility works as a sub-network controlled by a central management server (on the same network as the CPS). Any device (i.e. mobile phone, computer, hard drive) plugged into this sub-network is able to be accessed by the central management server and have its data erased. The central management server can then be accessed via an API to determine which devices have been 
erased and whether it was successful. Virtual assets requiring modelling will be the services which decide the process flow, storage of business process, Graphical User Interfaces (GUIs) both for operators and for customers logging in, security (authentication, authorisation and encryption) and the virtual models of the product \& factory. These key concepts to be modelled with a pictorial icon are shown in Table 1. RAMI4.0 will be evaluated based on how well the concepts can be represented on to RAMI4.0 and any difficulties discussed.

Table 1 - Scenario Concepts and Icons

\begin{tabular}{|c|c|c|c|}
\hline Aspect & Icon & Aspect & Icon \\
\hline Physical product & & $\begin{array}{c}\text { Supply chain member as a } \\
\text { user }\end{array}$ & 89 \\
\hline $\begin{array}{l}\text { RFID hardware for the } \\
\text { product to system } \\
\text { communication }\end{array}$ & Ya & Authentication & \\
\hline $\begin{array}{c}\text { A virtual representation of } \\
\text { the product }\end{array}$ & & Authorisation & \\
\hline $\begin{array}{l}\text { Web service to determine } \\
\text { next process of product } \\
\text { using recorded business } \\
\text { processes }\end{array}$ & & $\begin{array}{l}\text { A virtual model of the } \\
\text { factory }\end{array}$ & \\
\hline Business Processes & & $\begin{array}{l}\text { Encryption of information \& } \\
\text { data }\end{array}$ & \\
\hline Operator (human) & & $\begin{array}{l}\text { Interface for system } \\
\text { interaction }\end{array}$ & \\
\hline $\begin{array}{l}\text { Automated Process (data } \\
\text { erasure), stand-alone } \\
\text { interfaced system }\end{array}$ & $\stackrel{\circ}{=}$ & & \\
\hline
\end{tabular}

\section{Case Study Representation}

The concepts shown in Table 1 have been represented in Figure 3 on two of RAMI4.0's dimensions (software and hierarchy) to depict the system's functionality. The lifecycle axis was ignored as the scenario focuses on the refurbishment processes and not the transfer of information or products between lifecycle stages. This is particularly relevant for this case study as prior to devices arriving at the refurbishment facility there is little to no information, even basic details such as the number of devices expected are not always supplied let alone information on the device's specification or condition. 
For the selected scenario there are no field devices (e.g. smart sensors) or control devices (e.g. automated conveyors) this is due to the manual nature of the refurbishment process. The facility under scrutiny in this example has one work centre (production line), and so the representation of the enterprise (typically the sum of multiple work centres) can be seen as similar.

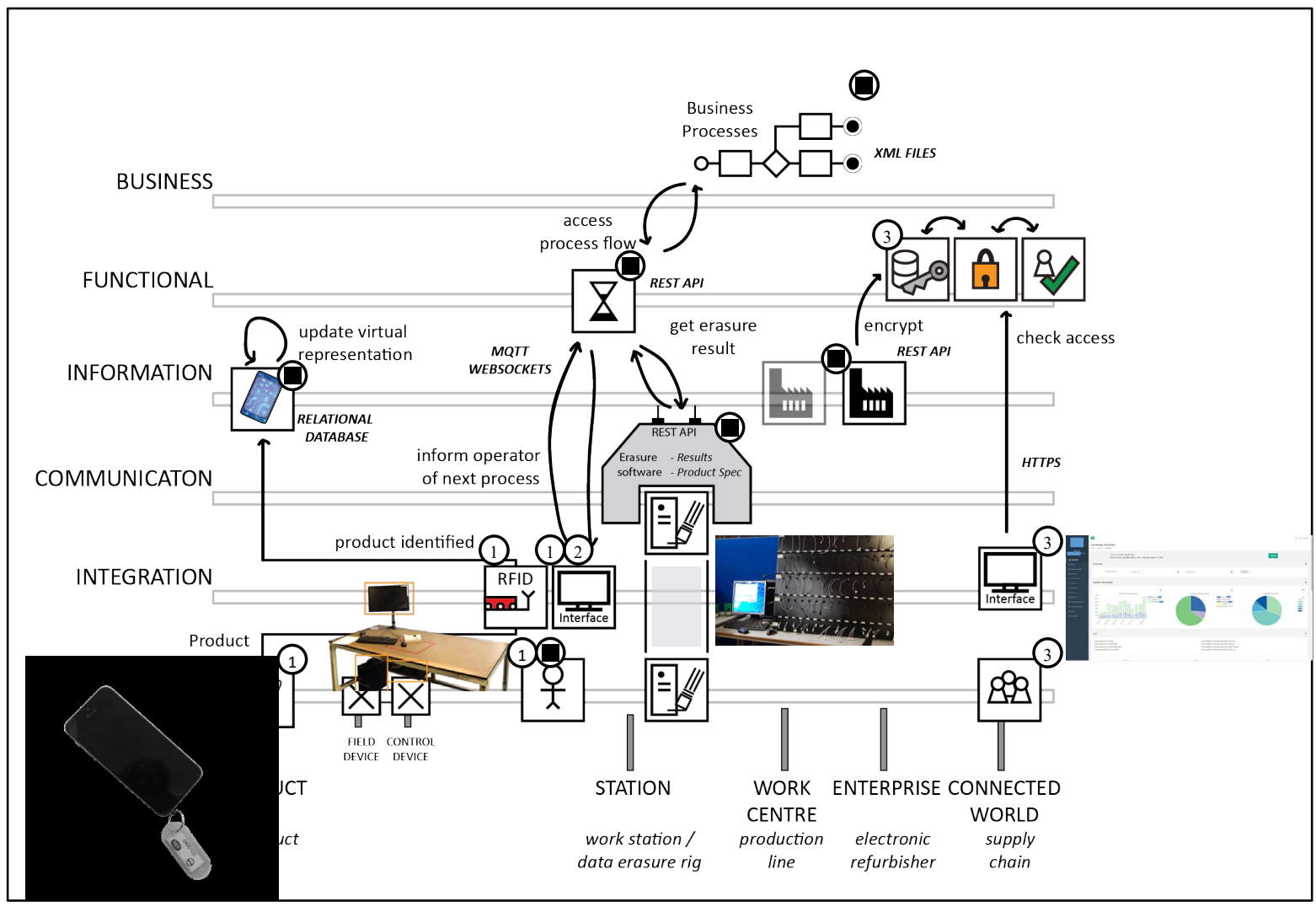

Figure 3 - CPS presented within [38] on RAMI4.0 showing the three scenarios

\subsection{Scenario 1: Moving of product to a workstation and being automatically identified}

RAMI4.0 clearly shows how physical assets, in this example an IT asset (mobile phone), are communicated with, allowing easy understanding that RFID is being used to track products within the facility and that the hardware is physically located at the workstations (shown in the integration layer). The representation depicts two stations where instances of processes occur. One station is a workstation for a manual process (in this example a repair) with a GUI to enter information and the other the automated erasure system (shown as having an administrative shell). 
As the operator places the product on to their repair workstation, the system identifies the product using its RFID tag as an event and executes an update of the product's virtual representation with its new location (in the information layer).

RAMI4.0 does not show however that the physical operator is interacting with the physical product (i.e. transporting).

\subsection{Scenario 2: Information on the product and the next process is displayed to the operator}

Once the workstation has identified the product (in the information layer), a detailed process history and product specification can be retrieved (from the virtual representation stored within a relational database). This extra information allows instructions for the current process to be delivered to the operator's interface (integration layer, station), based on the product's details. In this example, once the operator has carried out a repair and recorded the required process information, the CPS must determine the next process. This is a key part of the system functionality and is depicted as a service (part of a REST API) in the functional layer. It can be seen that this route decision service relies on business information (i.e. the refurbishment process flow) stored in the business layer. This business information is stored in an XML conversion of visual UML activity diagrams.

The 'erasure rig' used within the case study facility operates as a stand-alone system which allows connections and as such has been shown using the RAMI 4.0 administrative shell, Figure 3 ; it has an active communication capability as it is a networked device and it is administered as an entity giving it a code of CP34. While being shown with an administrative shell was decided as the correct method it was unsure how or if this should then be represented back on the main RAMI4.0 architecture view. It was also unclear how to represent the operator in the hierarchy axis as while humans are defined in the asset layer; they carry out a more diverse role than can be shown in the hierarchy layer. 


\subsection{Scenario 3: Supply chain member accessing real-time data to see the progress of product}

The third scenario is showing user/s from other companies within the supply chain accessing data on their products being refurbished within the facility.

The layers of RAMI4.0 allow representation of how much access is granted within this horizontal integration scenario. The data retrieved never needs to access a layer lower than the information layer (where product and refurbishment line virtual representations are held) and this access is granted through the security services on the functional layer.

The security functionality has been placed in the functional layer as they are grouped into services, and the data from the information layer can be shown as passed back through these and encrypted before leaving the refurbisher's system. It is not clear from the documentation on RAMI4.0 how security should be modelled and visualised only that it is an important aspect to consider.

How the supply chain members should be represented on the architecture was, like the operator, unclear, as humans they should be on the asset layer and as from another firm must be in the connected world hierarchy category. This does not allow for the representation of the different types of users who may be accessing the data.

\section{Discussion}

Using RAMI4.0 for this case study was effective in showing physical asset locations, connections and interactions. The types of technology used were able to be displayed but did complicate the diagram, and without many examples of RAMI4.0 in actual use, it is difficult to see how much detail was intended to be highlighted. Difficulties found were in the representation of (i) security-related features and (ii) of humans within the system.

Representation of security within an RA is not a unique consideration of Industry 4.0 and is similar to related fields such as the Internet of Things (IOT) systems. The loT paradigm is associated with CPS 
and Industry 4.0 and considered one of the key components supporting the future of manufacturing, smart cities and social networking [39]. There are strong similarities between loT and CPSs deployments in terms of research areas, both CPSs and IoT include how to design, deploy and support: (i) self-organisation, (ii) context and situational awareness control, (iii) symbiotic human-robot interaction and (iv) development methodologies for integration and implementation within industry [7]. One RA for loT systems is loT-A (Internet of Things- Architecture )[40]. IoT-A was developed as part of the EU's $7^{\text {th }}$ framework programme and was completed in 2013 this project [41] aimed to create the architectural foundations for the integration and interoperability of loT systems. While loTA considers security has a fundamental "functional group", shown in Figure 4, RAMI4.0 does not have any direct requirement for security to be modelled. The three icons from Table 1 representing security have been shown on loT-A's "functional view", Figure 4.

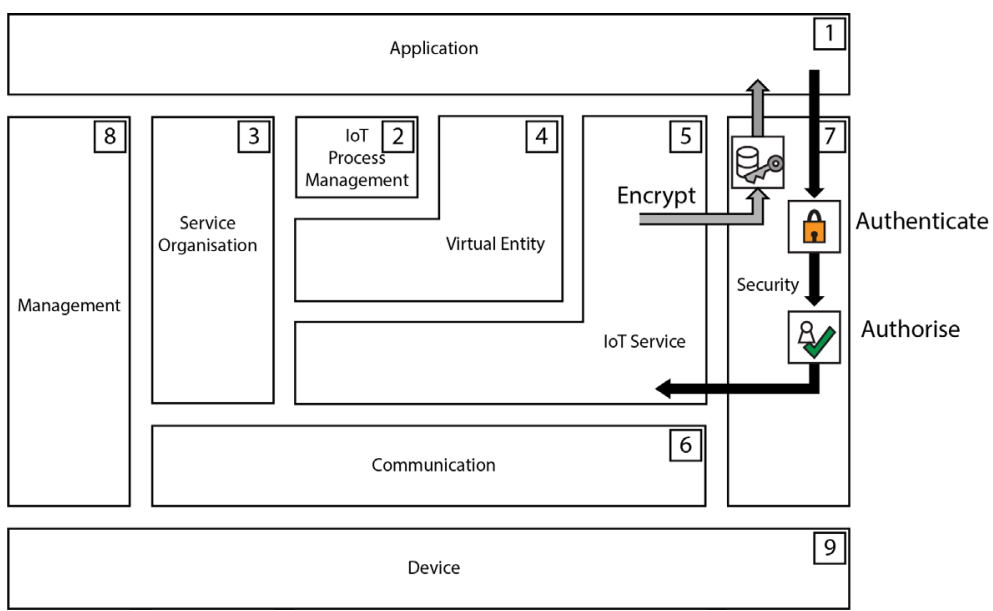

Figure 4 - IoT-A representation of security functionality

Security has been documented as a major challenge in CPSs [27] and is a concern of many industrialists [8]. The ability to show which security measures (at a high level) are being used and incorporated is important [7] and would aid the adoption of Industry 4.0 technologies and systems by industrialists. As such the first recommendation is to add a more detailed security aspect to RAMI4.0.

Secondly, RAMI4.0 does not seem to consider the human within the CPS nor if/how they should be modelled other than residing in the physical, asset layer. This could be because of a focus on automated manufacturing CPSs rather than looking towards a more CPHS approach. As an integral 
component of many systems, particularly in manufacturing, the inclusion of human representations needs to be considered [42]. This has led to the second recommendation which is that humans should be represented as a more fundamental aspect of Industry 4.0 moving from CPSs to CPHSs.

\subsection{Recommendation 1: Add a security aspect}

Security must be a fundamental consideration in any type of CPS. In addition, security cannot be the responsibility of a single layer and must be a factor within each layer within the RA. Ensuring that legitimate physical assets are connected, access can only be given to services and other connected facilities with the right authentication and authority permissions. Security should be considered in terms of Transmission, Physical and Data [43] functionalities. Transmission security covers the transfer of information and requests between layers, ensuring that users are authenticated, authorised, and that data is encrypted. It is also vital that connection records are maintained for any future fault-finding or computer forensic investigations [28]. Physical security ensures that physical objects that are transferring the data are secure and that the risk of tampering has been considered [43]. Data security ensures that correct data are entered into the system either through input validation or ensuring the authenticity of the source (linked to Transmission).

\subsection{Recommendation 2: Representation of "Humans in the Loop"}

Humans must be represented as physical objects/assets connected as part of the system. Their roles and requirements are equally as important as a hierarchy of connected assets. A long history of research relating to Human-Computer Interaction and Human Factors domains needs to be applied to the RA to aid the modelling of users of CPSs and Industry 4 [44]. Due to the variability and individuality of people, this recommendation represents a significant challenge. Without careful consideration, for example in contextually adaptive systems where automation takes more control, a "human out of the loop" situation may occur reducing the efficacy of the human in the system[16]. A wide range of factors may affect the behaviour of a "Human in the Loop", for example, personal factors such as skill, preference and experience[42], cultural [45], mental models [46], environmental and organisational 
influences[47]. The inclusion of human factors, ergonomics and $\mathrm{HCl}$ specialists within development teams for Industry 4.0 would aid in developing a more effective representation of the people in the system and improve RA veracity. Such multidisciplinary teams were indicated as fundamental to the success of Industry 4.0 [5], they were however not represented in much of the literature. One possible way of representing different types of users with an Industry 4.0 system would be to look at existing work into the classification of occupations and display this as a new axis on RAMI4.0. The International Standard Classification of Occupations (ISCO) -08 [48] is a standard which groups occupation titles into 10 roles groups; (1) Managers, (2) Professional (e.g. Engineering \& Finance Professionals), (3) Technicians and Associate Professionals (e.g. process control technicians and manufacturing supervisors), (4) Clerical Support Workers (e.g. general office), (5) Services and Sales Workers (e.g. personal services and sales workers), (6) Skilled Agricultural, Forestry and Fishery Workers, (7) Craft and Related Trade Workers, Plant (e.g. metal \& machinery and electrical and electronics trades workers) and (8) Machine Operators and Assemblers, (9) Elementary Occupations (e.g. cleaners, labourers in mining, construction, manufacturing and transport) and (0) Armed Forces Occupations. For representation on RAMI4.0, the authors have removed groups 5, 6 and 0 as they were focussed on industries other than manufacturing and merged groups 7 and 8 . These two groups $(7 \& 8)$ were merged under "Operator \& Machinist" due to the crossover between the two groups. The remaining six groups have been retitled to be more relevant to manufacturing; (1) Managers, (2) Engineers, (3) Technicians, (4) Clerks, (5) Operator \& Machinist and (6) Labourer.

\subsection{Representation on RAMI4.0}

These two recommendations have been incorporated into RAMI4.0 in Figure 5. The security aspect is currently shown as notations which are categorised as to whether they are related to transmission, data or physical security. A human axis has been displayed with the human manufacturing categories already discussed, Figure 5. The authors are not proposing the permeant removal of the original RAMI4.0 lifecycle axis, but that when representing high-level system functionality, within a single part 
of the life-cycle the ability to represent a hierarchy of human roles within Industry 4.0 CPHSs will allow easier communication of human-system, human-human and human-physical asset interactions.

The scenarios and icons from Figure 3 have been represented onto this altered RAMI4.0 and shows how the adaptations allow the modelling of the different user types (operators and clerks), shows the physical interaction between human and product and how the RA now gives a clearer method of how to represent security features.

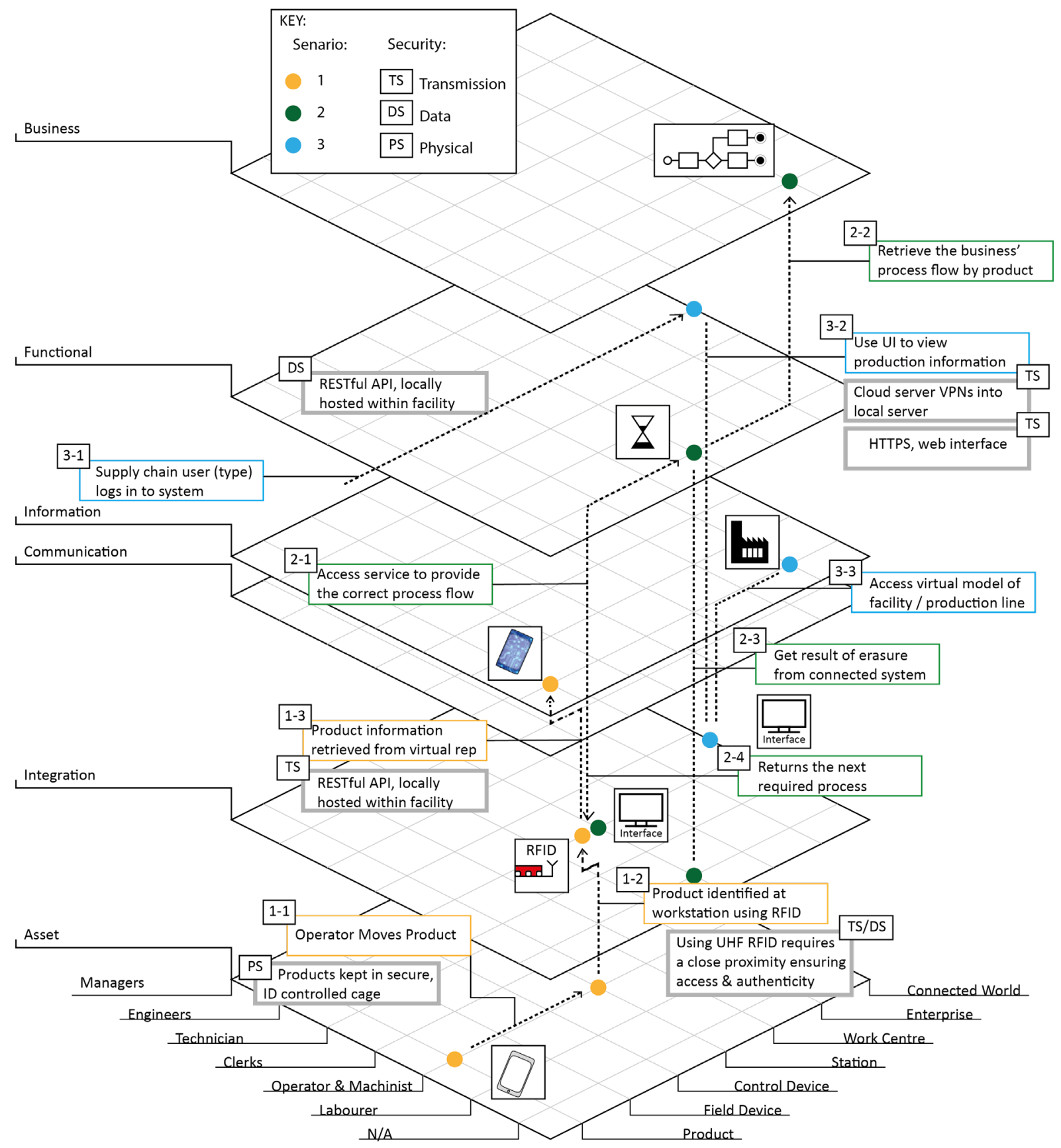

Figure 5 - Recommendations for RAMI4.0 


\section{Conclusion}

The purpose of this research was to look at the representation of a real CPS using RAMI4.0. While the system presented was not designed as Industry 4.0 (i.e. didn't look to utilise any Industry 4.0 communication protocols such as OPC-UA) it was created as a CPS, and therefore the functionality should be able to be represented. RAMI4.0 has been proposed to be used by a wide range of stakeholders including managers, experts and consultants looking to implement and use Industry 4.0 technology [1]. As such the architecture needs to be able to represent overlays of scenarios to effectively communicate fundamental functionality (such as those in Table 1). While RAMI4.0 has been designed to represent the integration of factory assets, it does not address the security aspects of CPSs (unlike IoT-A) for integration within supply chains and is unable to represent the important interactions of human resources within the CPSs [49].

Evaluating RAMI4.0 to represent a CPS for a real-world scenario has enabled 2 recommendations (security and human modelling) to be defined for modifications to the architecture as stepping stones towards migrating the current research-driven architecture to a more industrially relevant practicedriven RA. It has also been shown within this research that moving the focus to a CPHS would be more beneficial to Industry 4.0 to ensure humans are properly considered when Industry 4.0 systems are design and implemented.

\section{Acknowledgments}

The authors would like to thank EPSRC for the project "AIIM" [grant reference EP/K014137/1] that has supported this research.

\section{References}

[1] P. Adolphs, H. Bedenbender, D. Dirzus, M. Ehlich, U. Epple, M. Hankel, R. Heidel, M. Hoffmeister, H. Huhle, B. Karcher, H. Koziolek, R. Pichler, S. Pollmeier, F. Schewe, A. Walter, B. Waser, M. Wollschlaeger, Status Report - Reference Architecture Model Industrie 4.0 
(RAMI4.0), 2015. http://www.zvei.org/Downloads/Automation/5305 Publikation GMA Status Report ZVEI Reference Architecture Model.pdf.

[2] R. (Raj) Rajkumar, I. Lee, L. Sha, J. Stankovic, Cyber-physical systems: The next computing revolution, in: Proc. 47th Des. Autom. Conf. - DAC '10, ACM Press, New York, New York, USA, 2010: p. 731. doi:10.1145/1837274.1837461.

[3] E. Negri, L. Fumagalli, M. Macchi, A Review of the Roles of Digital Twin in CPS-based Production Systems, Procedia Manuf. 11 (2017) 939-948. doi:10.1016/j.promfg.2017.07.198.

[4] D. Gorecky, M. Schmitt, M. Loskyll, D. Zuhlke, Human-machine-interaction in the industry 4.0 era, in: 2014 12th IEEE Int. Conf. Ind. Informatics, IEEE, 2014: pp. 289-294. doi:10.1109/INDIN.2014.6945523.

[5] H. Kagermann, W. Wahlster, J. Helbig, Recommendations for implementing the strategic initiative INDUSTRIE 4.0 - Final report of the Industrie 4.0 Working Group, 2013. http://www.acatech.de/fileadmin/user_upload/Baumstruktur_nach_Website/Acatech/root/ de/Material_fuer_Sonderseiten/Industrie_4.0/Final_report_Industrie_4.0_accessible.pdf.

[6] Deloitte, Deloitte Review: Industry 4.0 : Are you ready?, 2018.

[7] L. Wang, M. Törngren, M. Onori, Current status and advancement of cyber-physical systems in manufacturing, J. Manuf. Syst. (2015). doi:10.1016/j.jmsy.2015.04.008.

[8] BDO LLP, Industry 4.0 Report, 2016.

[9] E.M. Geisberger, M. Broy, Living in a networked world : Integrated research agenda CyberPhysical Systems (agendaCPS)(acatech STUDY), Munich, Germany, 2015.

[10] M. Krugh, L. Mears, A complementary Cyber-Human Systems framework for Industry 4.0 Cyber-Physical Systems, Manuf. Lett. 15 (2018) 89-92. doi:10.1016/j.mfglet.2018.01.003.

[11] S. Martínez-Fernández, C.P. Ayala, X. Franch, H. Martins Marques, Benefits and drawbacks of reference architectures, in: 2013: pp. 307-310. doi:10.1007/978-3-642-39031-9_26. 
[12] M. Galster, Software Reference Architectures: Related Architectural Concepts and Challenges, in: Proc. 1st Int. Work. Explor. Component-Based Tech. Constr. Ref. Archit. - CobRA '15, ACM Press, New York, New York, USA, 2015: pp. 5-8. doi:10.1145/2755567.2755570.

[13] S. Martínez-Fernández, C. Ayala, X. Franch, H.M. Marques, Artifacts of software reference architectures: A case study, in: Association for Computing Machinery, 2014. doi:10.1145/2601248.2601282.

[14] P. Hehenberger, B. Vogel-heuser, D. Bradley, B. Eynard, Design, Modelling, Simulation and Integration of Cyber Physical Systems : Methods and Applications, Elsevier. 82 (2016) 273-289. doi:10.1016/j.compind.2016.05.006.

[15] R. Poovendran, Cyber-Physical Systems: Close Encounters Between Two Parallel Worlds [Point of View], Proc. IEEE. 98 (2010) 1363-1366. doi:10.1109/JPROC.2010.2050377.

[16] T.B. Sheridan, R. Parasuraman, Human-Automation Interaction, Rev. Hum. Factors Ergon. 1 (2005) 89-129. doi:10.1518/155723405783703082.

[17] G. Grote, J. Weyer, N.A. Stanton, Beyond human-centred automation - concepts for humanmachine interaction in multi-layered networks, Ergonomics. 57 (2014) 289-294. doi:10.1080/00140139.2014.890748.

[18] F. Fruggiero, S. Riemma, Y. Ouazene, R. Macchiaroli, V. Guglielmi, Incorporating the Human Factor within Manufacturing Dynamics, IFAC-PapersOnLine. 49 (2016) 1691-1696. doi:10.1016/j.ifacol.2016.07.825.

[19] G. Klein, B. Shneiderman, R.R. Hoffman, K.M. Ford, Why Expertise Matters: A Response to the Challenges, IEEE Intell. Syst. 32 (2017) 67-73. doi:10.1109/MIS.2017.4531230.

[20] D.H. Autor, Why Are There Still So Many Jobs? The History and Future of Workplace Automation, J. Econ. Perspect. 29 (2015) 3-30. doi:10.1257/jep.29.3.3.

[21] X. Yao, Y. Lin, Emerging manufacturing paradigm shifts for the incoming industrial revolution, Int. J. Adv. Manuf. Technol. 85 (2016) 1665-1676. doi:10.1007/s00170-015-8076-0. 
[22] P. Jiang, J. Leng, K. Ding, Social manufacturing: A survey of the state-of-the-art and future challenges, in: 2016 IEEE Int. Conf. Serv. Oper. Logist. Informatics, IEEE, 2016: pp. 12-17. doi:10.1109/SOLI.2016.7551654.

[23] F.-Y. Wang, The Emergence of Intelligent Enterprises: From CPS to CPSS, IEEE Intell. Syst. 25 (2010) 85-88. doi:10.1109/MIS.2010.104.

[24] C. Scheuermann, S. Verclas, B. Bruegge, Agile Factory - An Example of an Industry 4.0 Manufacturing Process, in: 2015 IEEE 3rd Int. Conf. Cyber-Physical Syst. Networks, Appl., IEEE, 2015: pp. 43-47. doi:10.1109/CPSNA.2015.17.

[25] S.K. Sowe, E. Simmon, K. Zettsu, F. de Vaulx, I. Bojanova, Cyber-Physical-Human Systems: Putting People in the Loop, IT Prof. 18 (2016) 10-13. doi:10.1109/MITP.2016.14.

[26] R. Cloutier, G. Muller, D. Verma, R. Nilchiani, E. Hole, M. Bone, The Concept of Reference Architectures, Syst. Eng. 13 (2009) n/a-n/a. doi:10.1002/sys.20129.

[27] E.A. Lee, Cyber Physical Systems: Design Challenges, in: 2008 11th IEEE Int. Symp. Object Component-Oriented Real-Time Distrib. Comput., IEEE, 2008: pp. 363-369. doi:10.1109/ISORC.2008.25.

[28] C. Esposito, A. Castiglione, B. Martini, K.-K.R. Choo, Cloud Manufacturing: Security, Privacy, and Forensic Concerns, IEEE Cloud Comput. 3 (2016) 16-22. doi:10.1109/MCC.2016.79.

[29] S. Ghimire, F. Luis-Ferreira, R. Jardim-Gonçalves, Towards Self-evolutionary Cyber Physical Systems., ISPE CE. (2014). http://ebooks.iospress.nl/volumearticle/37904 (accessed July 4, 2017).

[30] S. Angelov, J.J.M. Trienekens, P. Grefen, Towards a Method for the Evaluation of Reference Architectures: Experiences from a Case, in: Softw. Archit., Springer Berlin Heidelberg, Berlin, Heidelberg, 2008: pp. 225-240. doi:10.1007/978-3-540-88030-1_17.

[31] IEC, IEC 62264-1: 2013, Enterprise-control system integration -- Part 1: Models and terminology, 2013. http://www.iso.org/iso/catalogue_detail.htm?csnumber=57308. 
[32] IEC, IEC 61512-1: 1997, Batch Control - Part 1: Models and terminology, (1997). http://www.enstandard.eu/iec-61512-1-1997-batch-control-part-1-models-andterminology/?gclid=CjwKEAjwi9K4BRCQzq7d1c6A_XASJABueAO2zVkTcenOunYz36TXevls33QpwzoOrmE9cPptS6dsxoCVJjw_wcB.

[33] J. Frysak, C. Kaar, C. Stary, Benefits and pitfalls applying RAMI4.0, in: Proc. - 2018 IEEE Ind. Cyber-Physical Syst. ICPS 2018, 2018: pp. 32-37. doi:10.1109/ICPHYS.2018.8387633.

[34] M.A. Babar, I. Gorton, Comparison of Scenario-Based Software Architecture Evaluation Methods, in: 11th Asia-Pacific Softw. Eng. Conf., IEEE, n.d.: pp. 600-607. doi:10.1109/APSEC.2004.38.

[35] P. Shanmugapriya, R.M. Suresh, Software Architecture Evaluation Methods - A survey, Int. J. Comput. Appl. 49 (2012) 975-8887. doi:10.5120/7711-1107.

[36] A. Patidar, U. Suman, A survey on software architecture evaluation methods, 49 (2015) 967972. http://ieeexplore.ieee.org/xpls/abs_all.jsp?arnumber=7100391 (accessed July 5, 2016).

[37] S. Angelov, P. Grefen, D. Greefhorst, A framework for analysis and design of software reference architectures, Inf. Softw. Technol. 54 (2012) 417-431. doi:10.1016/j.infsof.2011.11.009.

[38] R.G. Sharpe, P.A. Goodall, A.D. Neal, P.P. Conway, A.A. West, Cyber-Physical Systems in the reuse, refurbishment and recycling of used Electrical and Electronic Equipment, J. Clean. Prod. 170 (2018) 351-361. doi:10.1016/J.JCLEPRO.2017.09.087.

[39] L. Da Xu, W. He, S. Li, Internet of Things in Industries: A Survey, IEEE Trans. Ind. Informatics. 10 (2014) 2233-2243. doi:10.1109/TII.2014.2300753.

[40] S.K. Datta, C. Bonnet, N. Nikaein, An loT gateway centric architecture to provide novel M2M services, in: 2014 IEEE World Forum Internet Things, IEEE, 2014: pp. 514-519. doi:10.1109/WFIoT.2014.6803221.

[41] IoT-A, IoT-A Explanation, (2017). http://www.meet-iot.eu/iot-a-explanation.html (accessed December 12, 2017). 
[42] S.K. Sowe, E. Simmon, K. Zettsu, F. De Vaulx, I. Bojanova, Cyber-Physical-Human Systems: Putting People in the Loop, IT Prof. 18 (2016) 10-13. doi:10.1109/MITP.2016.14.

[43] L. Hu, N. Xie, Z. Kuang, K. Zhao, Review of Cyber-Physical System Architecture, in: 2012 IEEE 15th Int. Symp. Object/Component/Service-Oriented Real-Time Distrib. Comput. Work., IEEE, 2012: pp. 25-30. doi:10.1109/ISORCW.2012.15.

[44] T. Clemmensen, Four approaches to user modelling - A qualitative research interview study of HCl professionals' practice, Interact. Comput. 16 (2004) 799-829. doi:10.1016/j.intcom.2004.04.009.

[45] G. Hofstede, Culture's consequences: comparing values, behaviors, institutions and organizations across nations, 2nd ed, SAGE Publications, Inc., 2001.

[46] N. Moray, Identifying mental models of complex human - machine systems, Int. J. Ind. Ergon. 22 (1998) 293-297. doi:http://dx.doi.org/10.1016/S0169-8141(97)00080-2.

[47] M. Maguire, Using Human Factors Standards to Support User Experience and Agile Design, in: C. Stephanidis, M. Antona (Eds.), Univers. Access Human-Computer Interact. Des. Methods, Tools, Interact. Tech. Elnclusion, Springer US, 2013: pp. 185-194. doi:10.1007/978-3-64239188-0_20.

[48] International Labour Organization (ILO), ISCO-08, International Standard Classification of Occupations, 2012. http://www.ilo.org/public/english/bureau/stat/isco/docs/publication08.pdf.

[49] P. Fantini, M. Pinzone, M. Taisch, Placing the operator at the centre of Industry 4.0 design: Modelling and assessing human activities within cyber-physical systems, Comput. Ind. Eng. (2018). doi:10.1016/J.CIE.2018.01.025. 